\title{
POSITION ACCURACY STUDY OF USING PORTABLE USB GPS ANTENNA IN OPEN AND CLOSED SPACES
}

\author{
AISYAH, SAMO* AND MOHD NOOR \\ Faculty of Ocean Engineering Technology and Informatics, Universiti Malaysia Terengganu, 21030 Kuala Nerus, \\ Terengganu, Malaysia
}

*Corresponding author: kbsamo2011@gmail.com

http://doi.org/10.46754/umtjur.2021.07.013

\begin{abstract}
This research involved the positional accuracy study of portable Global Positioning System (GPS) in open and closed spaces. The project has several phases; the first phase consists of setting the portable GPS antenna on the laptop computer and running the u-center data recording application software for raw data recording. The second phase involves data filtration, extraction of position information both for open and closed spaces for analysis. The next stage generation of results including the determining means of latitude and longitude errors and comparing positional accuracy in open and closed spaces. The errors between positions in open and closed spaces were determined for comparison based on selected known locations. The results are plotted into real latitude and longitude scale to show the position acquired. The result in open and closed spaces were finally statistically compared. The pattern of positions accuracy for open and closed space indicates larger longitude error compared to latitude error varying between 1-15 meters in terms of range error from the mean. Test for known positions using ANOVA indicate significant difference between locations acquired in open and closed spaces.
\end{abstract}

Keywords: GPS, accuracy, different spaces, GPS errors

\section{Introduction}

The Global Positioning System (GPS) has been used widely every day for different purposes and applications. GPS was developed in early 1970s and since then it has been studied extensively by researchers and this has resulted in numerous publications i.e., conference presentations, journal papers, books, etc. Navy Navigation Satellite System (NNSS) was first developed for US military relying on polar orbiting orbits. Later a more advanced system known as GPS was tested and developed initially for military use and later for commercial use. Today GPS system are fully operational regardless of weather conditions. Recent developments include other systems developed by the Russian - GLONASS, the European (GALILEO) and BeiDou (China). Each system relies on their own sets of satellites. All these systems can be referred as Global Navigation Satellite System (GNSS).
The main reason of this project was to assess and compare the positional accuracy by using cheap commercially available GPS antenna system and u-centre freeware by acquiring data streams from satellites meant for the public use. The other objective is to make comparison on the positional accuracy when receiving signals under different conditions namely in open and closed spaces. Hypothetically, the accuracy of the GPS will be reduced when all the signals emitted by the satellites are blocked by some buildings or obstructions by other structures. Use of GPS is growing as a means for determining positioning information in many scientific fields. GPS is employed in environmental studies, biological and biomechanical studies, social sciences, meteorology, military applications, archeology, navigation, mapping, surveying, and more as stated by Arnold and Zandbergen, (2011). Worldwide GPS innovation has changed the world which now we rely upon it for exploring vehicles, for course finding and we use it in our 
regular daily existences to extricate data about our areas and to follow our developments (SiłaNowicka \& Fotheringham, 2019). A low-cost portable antenna GPS receiver which can easily be attached to laptop computers was used to collect data. It is cheap, affordable and capable to collect a large number of data comparable to expensive built-in GPS (Forin-Wiart et al., 2015). Figure 1 shows the GPS antenna system.

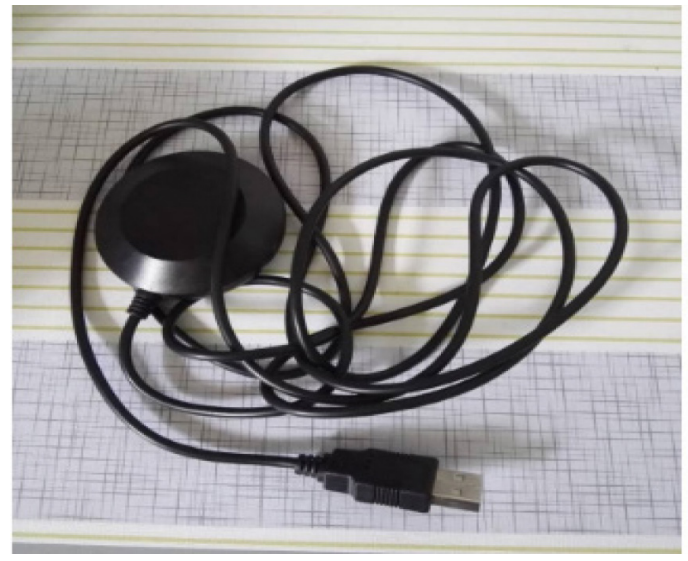

Figure 1: Antenna of the GPS system used to collect data transmitted by satellites.

In our daily life, Global Navigation Satellite System (GNSS) indeed plays a significant role for providing autonomous geo-spatial positioning information (Shi et al., 2017). The multipath effects are the major source of error in GPS differential positioning (Guo et al., 2014). The antenna receiver will acquired the strongest signal from the orbiting satellites in an open space while in closed spaced the received signals are much weaker and the multipath effects will cause them to have different results in position accuracy as the signals have to travel further. In this project, the position data finally will be statistically tested based on several sets of data collected at predetermined location (both in open and closed spaces) by a portable GPS antenna system capturing data using u-center software.

At any one time the GPS receiver is providing us with different data set by different set of satellites circulating along their orbits. The concept of using reflected GPS signals for environmental sensing was first introduced by Martin-Neira (1993). But, when we want to find very accurate position by using simple GPS receiver, we need to take the average position. Essentially any GNSS system measures the distance/range between the satellite transmitting the signal to the receiver. Using several satellites (at least 4) the receiver with the software determines several position lines from which a fix (or position) is determined i.e. latitude and longitude values that could be plotted in a geographical chart/map. The main error of travelling of electromagnetic waves and time signal error (due to internal clock accuracy) are being affected by the atmospheric and ionospheric conditions (Skeivalas et al., 2018). Therefore, the average positions determined based on large numbers of data will provide better position provided the receiver unit is kept at the same position. Generally, the GPS position obtained is not exact because of the receiver acquired data from different satellites which continuously move along their orbits. The dissimilar shapes of satellites orbits moving at different altitude will suffer from different perturbative forces, especially solar radiation pressure and atmospheric drag, which cannot be modeled appropriately (Zeng et al., 2018). Additionally, the GPS receiver that are receiving both direct or indirect signals usually will cause position errors as affected from multipath echoes (Deep et al., 2018). GPS's weak signals 
received are instable due to multipath signals caused by external factors such as the presence of high buildings around the receiver, in tunnels, and closed situations (Guo et al., 2014). Furthermore, the GPS signal quality and strength that broadcast by satellite availability and Geometric Dilution of Precision (GDOP) plays a major role in GPS positional accuracy caused by satellite geometry at a particular time along its own orbit. In addition, GPS technology can precisely register the spatiotemporal elements of activity-travel behaviour, travel characteristics should to be imputed from the information (van Dijk 2018) but this is beyond our project. The GPS data provided when using smartphones for example can suggestively increase the efficiency of travel studies and also quality of those data collected (Marra et al. 2019) that provide the user's position continuously.

There is no specific time required to acquire GPS data in this research project as we can receive the signals at any time - day and night. The time taken to take in one set of data by using u-center program depends on how many data position are required. The more position data to be taken the longer the time needed. In this project several (100-200) sets of data or messages were taken. Data processing is carried out first by eliminating the unwanted data messages listing only time, latitude and longitude. Most data were collected within UMT campus and at specified locations in Selangor.

\section{Materials and Methods}

For this project, we experimented by testing position data at different fixed locations both in open (5 locations) and closed (5 locations) spaces. A simple, low cost commercially available GPS antenna was used and data acquisitions were recorded using a U-center GNSS evaluation software for a duration of between one to minutes at each location. The data acquisition system record signals randomly from different sets of satellites passing over head of the receiver at that time. The raw position messages acquired were save in text format and then read by Excel spreadsheet where only information of interest were copied for further analysis. The process flow is as shown in figure 2. 


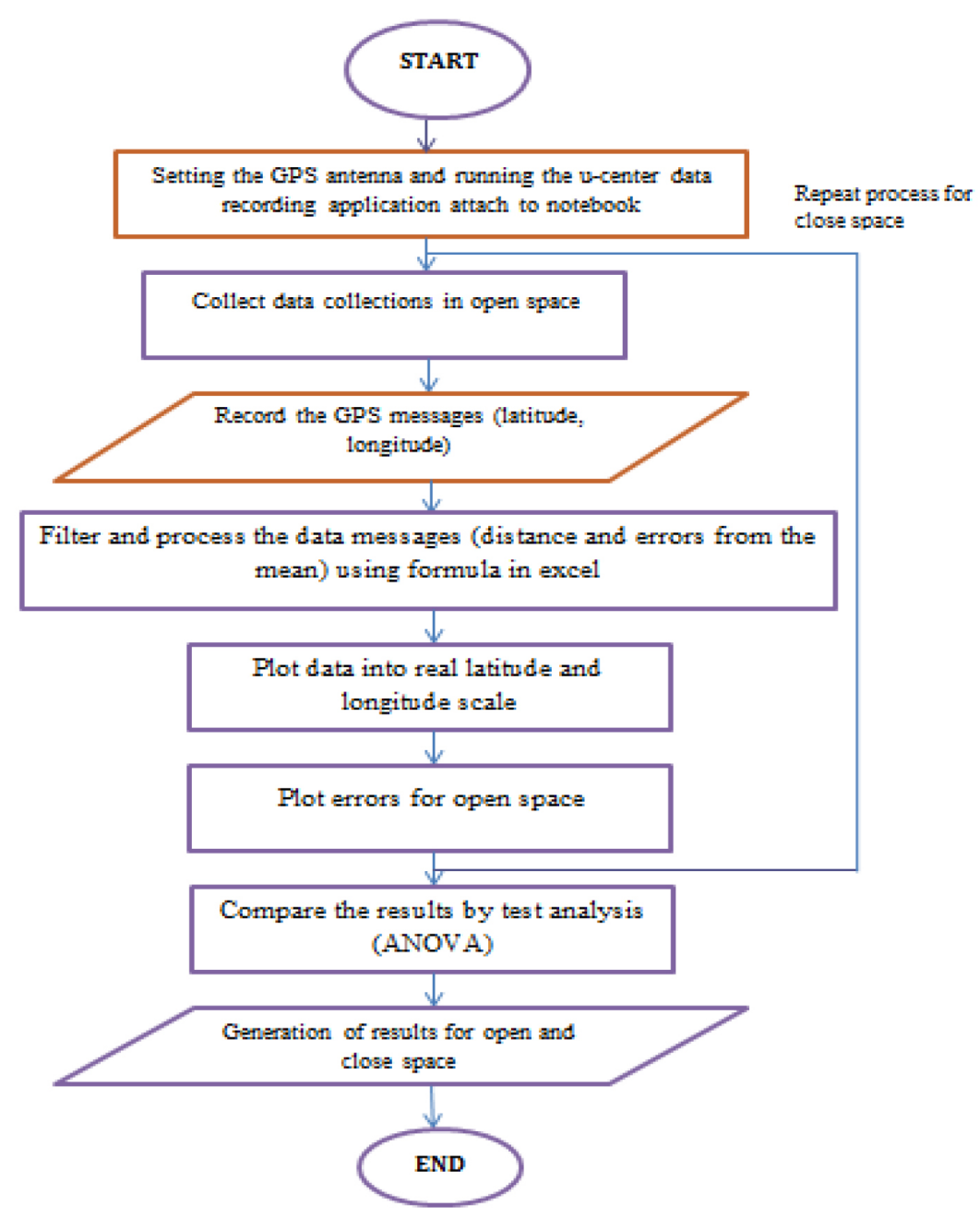

Figure 2: Process flow for data acquisition and analysis of the project

\section{The Data in open and closed Spaces}

An example of open space is in the middle of a field free of trees or building and mountains which can obstruct the USB antenna from effectively receiving the GPS signals. In the case of closed space data were acquired in places such as next to the building or inside a building where at that locations the USB antenna partially receive the signal both direct and indirect signals bounces off of nearby structures such as buildings. In the room the signals received were generally weaker while when placed at the side of the building halve of the signals were received.
Regardless of weather conditions, usually, a GPS receiver will receive streams of data from several visible satellites within the horizon. Besides, the system will select the strongest signals and the location geometry of the satellites (ephemeris) relative to the receiver. The presence of any obstacle naturally blocks the signals from arriving at the receiver. Figures $3 \mathrm{a}$ and $3 \mathrm{~b}$ show the locations of the antenna receiver at open and closed spaces (next to building). 


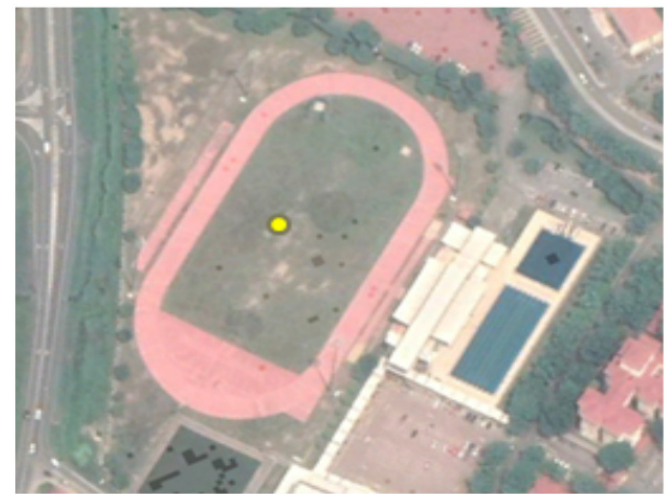

Figure 3a: Field UMT for open space's location

\section{U-center application for collecting data}

The u-center software collects and displays NMEA message structure including GPS

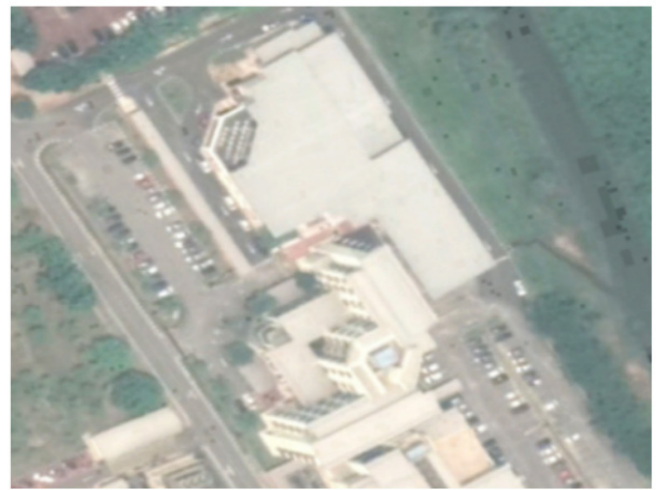

Figure 3b: Laboratory in UMT for closed space

position, time stamp, latitude, longitude, signal quality indicator, number of satellites, Figure 4 is the snapshot of u-center displaying the satellites, signal strengths etc.

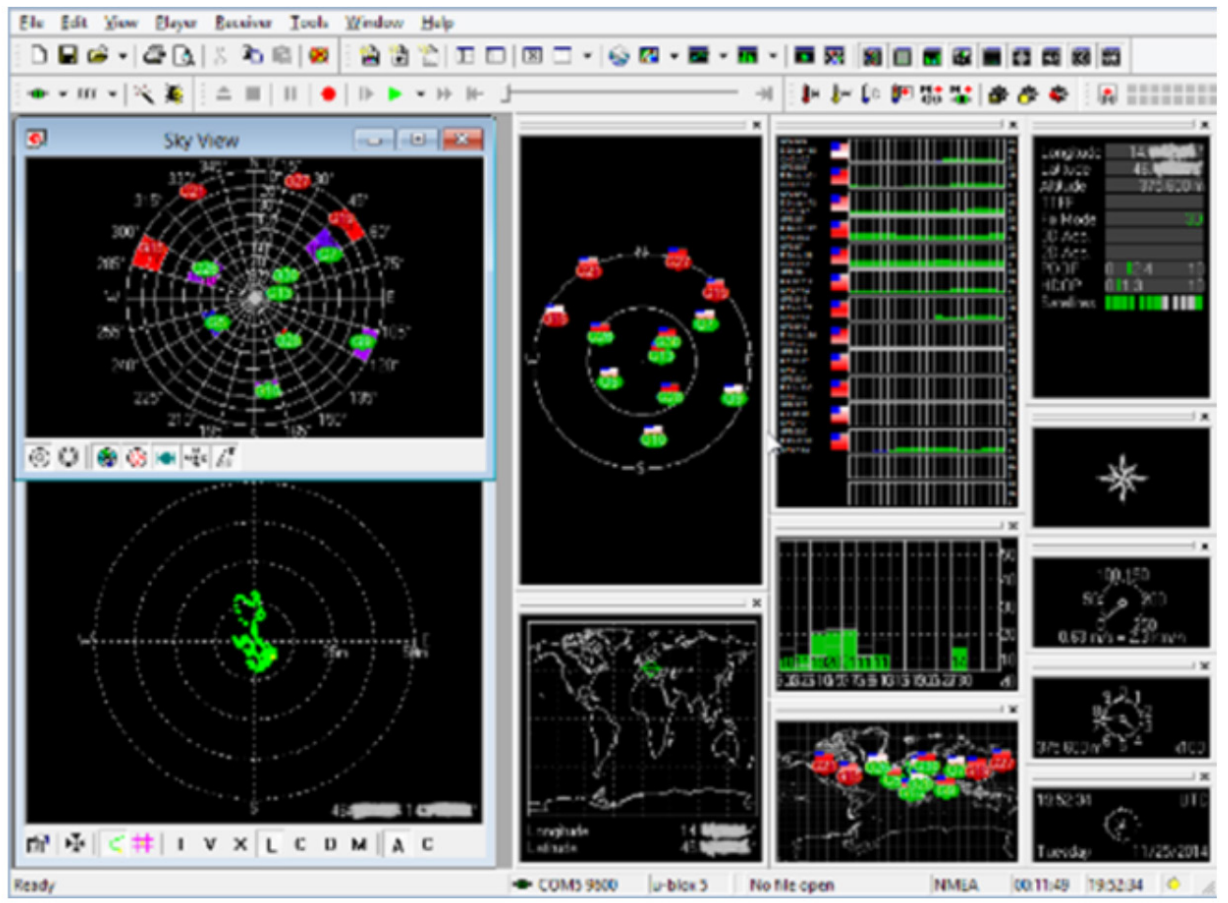

Figure 4: Snapshots of u-center software displaying the relative satellites position and position plot and signal levels

\section{Data Recording Process}

The u-center software once running will continuously record streams of data in the form of messages every second and similarly received by other GPS receivers. Random satellites will transmit the signal to USB GPS antenna. Therefore, data position captured by the GPS will not be the same. U-center software once running will display position information 
in various graphical formats. The raw data including time stamp and the computed location information were then saved as text file readable by any spreadsheet program including Microsoft
Excel (Fgure 5). Figure 6 show a sample of text message and the extracted location information (Figure 7).

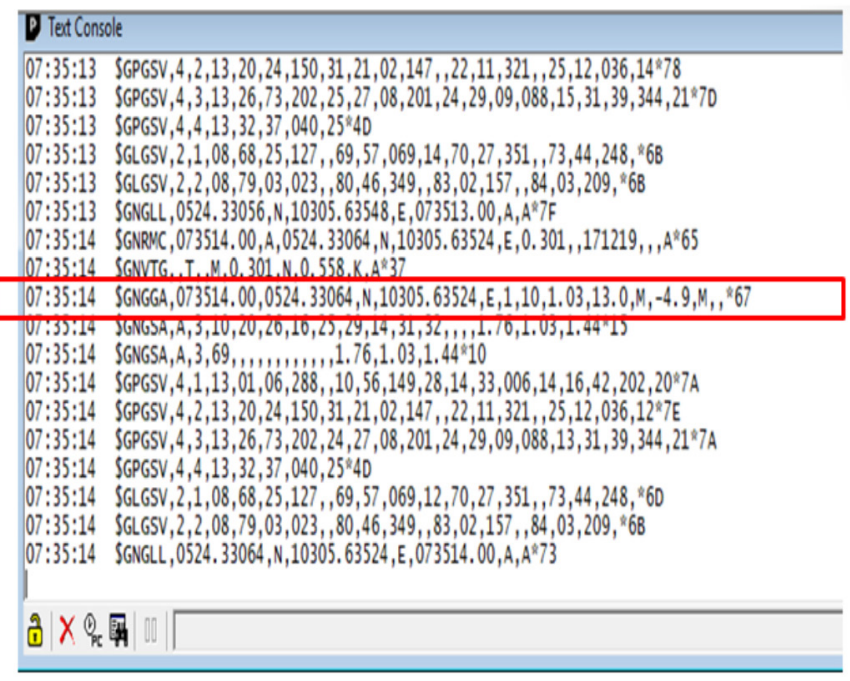

Figure 5: The text messages from the u-center software

\begin{tabular}{|c|c|c|c|c|c|c|c|c|c|c|c|c|c|c|c|c|c|}
\hline 9:10:245 SaNGLL & $5246837 \mathrm{~N}$ & & $10305.12 \mathrm{E}$ & & S1024A & $D^{*} 7$ & & & & & & & & & & & \\
\hline 9:10:25 \$GNRR/C & C $91025 \mathrm{~A}$ & & $5246837 \mathrm{~N}$ & & $10305.12 \mathrm{E}$ & & 0.054 & 135519 o" & & & & & & & & & \\
\hline 9:10:25 STNNTG & 1 & & $0.064 \mathrm{~N}$ & & $0.119 \%$ & $D^{*} 3$ & & & & & & & & & & & \\
\hline 9:10:25\$SONGGA & 91025 & $5837 \mathrm{~N}$ & & $05.12 \mathrm{E}$ & & 2 & 12 & 1.52 & $-43 N$ & & $4.5 \mathrm{~N}$ & & 000370 & & & & \\
\hline 9:10:25559NGSA & & 3 & 41 & 40 & 7 & 30 & 5 & 6 & 2 & 19 & 17 & 1.95 & 1.521 .2 & & & & \\
\hline 9:10:25 SGNGSA & & 3 & 75 & 85 & 74 & 1.95 & 15212 & $1.22^{2} 1 \mathrm{~A}$ & & & & & & & & & \\
\hline 9:10:25 5 SPGSY & 4 & 1 & 14 & 2 & 30 & 257 & 35 & 3 & 12 & 45 & 5 & 6 & 29 & 40 & 6 & 54 & $300287:$ \\
\hline 9:10:25 \$GPGSY & 4 & 2 & 14 & 7 & 10 & 158 & 15 & 9 & 14 & 133 & 13 & 1 & 299 & 17 & 27 & $317^{7}$ & \\
\hline 9:10:2559PGSY & 4 & 3 & 14 & 19 & 24 & 340 & 23 & 23 & 1 & 100 & 28 & 56 & 51 & 30 & 35 & $98233^{5}$ & \\
\hline 9:10:25 S9PGSY & 4 & 4 & 14 & 40 & 35 & 265 & 33 & 41 & 66 & $25531^{47}$ & & & & & & & \\
\hline 9:10:25 \$StLCSV & 3 & 1 & 10 & 69 & 22 & $\infty$ & 70 & 30 & 144 & 71 & 6 & 138 & 21 & 73 & 58 & 181867 & \\
\hline 9:10:25 SolasV & 3 & 2 & 10 & 74 & 63 & 303 & 15 & 75 & 11 & 329 & 26 & 30 & 3 & 159 & 84 & 14 & $9^{\prime} 6 \mathrm{~F}$ \\
\hline 9:10:25 5olcsv & 3 & 3 & 10 & 85 & 21 & 314 & 27 & 86 & 3 & $263^{2} 63$ & & & & & & & \\
\hline 9:10:25 \$aNGLL & $5246837 \mathrm{~N}$ & & 10305.12 E & & $5105 \mathrm{~A}$ & $0^{*} 7$ & & & & & & & & & & & \\
\hline 9:10:26 50NR/C & C $91026 \mathrm{~A}$ & & $5246837 \mathrm{~N}$ & & 10305.12E & & 0.075 & $135519 \mathrm{D}^{\prime \prime}$ & & & & & & & & & \\
\hline 9:10:26 SaNvTG & $T$ & & $0.075 \mathrm{~N}$ & & 0.1331 & $D^{*} 3$ & & & & & & & & & & & \\
\hline 9:10:265SONGGA & 910265 & $5837 \mathrm{~N}$ & & $05.12 \mathrm{E}$ & & 2 & 12 & 1.52 & $-43 \mathrm{~N}$ & & $4.9 \mathrm{~N}$ & m & 0087 & & & & \\
\hline 9:10:265 SGNGSA & & 3 & 41 & 40 & 7 & 30 & 5 & 6 & 2 & 19 & 17 & 1.95 & 1.521 .22 & $22^{2} \div C$ & & & \\
\hline 9:10:26 SGNGSA & & 3 & 75 & 85 & 74 & 1.95 & 1.521 .2 & $2.22^{2} 1 \mathrm{~A}$ & & & & & & & & & \\
\hline 9:10:26 SGPGSY & 4 & 1 & 14 & 2 & 30 & 257 & 35 & 3 & 12 & 45 & 5 & 6 & 29 & 40 & j & 54 & $3002 \pi^{7} 71$ \\
\hline
\end{tabular}

Figure 6: Information message from u-center shows the time stamps and location of receiver for every second. 


\begin{tabular}{|l|l|l|l|}
\hline $8: 02: 42$ \$GNGGA & 80242 & $524.683 \mathrm{~N}$ & $10305.12 \mathrm{E}$ \\
\hline $8: 02: 43$ \$GNGGA & 80243 & $524.683 \mathrm{~N}$ & $10305.12 \mathrm{E}$ \\
\hline $8: 02: 44$ \$GNGGA & 80244 & $524.683 \mathrm{~N}$ & $10305.12 \mathrm{E}$ \\
\hline $8: 02: 45$ \$GNGGA & 80245 & $524.683 \mathrm{~N}$ & $10305.12 \mathrm{E}$ \\
\hline $8: 02: 46$ \$GNGGA & 80246 & $524.683 \mathrm{~N}$ & $10305.12 \mathrm{E}$ \\
\hline $8: 02: 47$ \$GNGGA & 80247 & $524.6829 \mathrm{~N}$ & $10305.12 \mathrm{E}$ \\
\hline $8: 02: 48$ \$GNGGA & 80248 & $524.6829 \mathrm{~N}$ & $10305.12 \mathrm{E}$ \\
\hline $8: 02: 49$ \$GNGGA & 80249 & $524.6829 \mathrm{~N}$ & $10305.12 \mathrm{E}$ \\
\hline $8: 02: 50$ \$GNGGA & 80250 & $524.6829 \mathrm{~N}$ & $10305.12 \mathrm{E}$ \\
\hline $8: 02: 51$ \$GNGGA & 80251 & $524.6829 \mathrm{~N}$ & $10305.12 \mathrm{E}$ \\
\hline $8: 02: 52$ \$GNGGA & 80252 & $524.6829 \mathrm{~N}$ & $10305.12 \mathrm{E}$ \\
\hline
\end{tabular}

Based on the position data in latitude and longitude the mean values for both were determined and the difference from the mean was then used for graphical plots and determination of error. In this project the mean positions under closed and open spaces were assumed to be the best position

\section{Formula for data processing}

The mean position computed using n-number of position information in this case was assumed to be the right position of the receiver. And in geographical grid the would-be position is where the Latitude (y-coordinate) and Longitude (x-coordinate) lines crossed.

Using individual position data, the distribution of $\mathrm{X}$ and $\mathrm{Y}$ from the mean (i.e. the latitude and longitude errors could be plotted. The position co-ordinates were determined over a specified time frame using averaging formulae:

$$
\begin{aligned}
& \mathbf{X}_{\mathrm{avg}}=\frac{\sum_{i=1}^{n} \text { Clat } \mathrm{i}}{n} \\
& \mathbf{y}_{\mathrm{avg}}=\frac{\sum_{i=1}^{n} \text { Clon } \mathrm{i}}{n}
\end{aligned}
$$

where, Clati and Cloni are the positions indicated by latitudinal and longitudinal values and $\mathrm{n}$ is the number of GPS points processes (Schrader et al., 2016). For individual error the difference between the reference point (mean position) and each individual GPS position recorded by the receiver was determined. Finally to determine the error from the mean, one Degree of arc on the earth surface (or 60 ' minutes) was taken to have an equivalent distance of $111000 \mathrm{~m}$. In nautical measurement one nautical mile has an equivalent distance of 1852 meters.

\section{Analysis and Comparison}

They are then converted into geographical format to generate the plots and for determining positioning errors. The results (between open and closed spaces) were then compared for accuracy by using test statistics (ANOVA).

\section{Results and Discussion}

Data processing for an open and closed spaces

Data samples for open and closed spaces are as shown in Table 1 indicating the latitude and longitude for both open and closed spaces. 
Table 1: Sample Data recordings of latitude and longitude for open and closed space.

\begin{tabular}{cccc}
\hline \multicolumn{2}{c}{ Open Space } & \multicolumn{2}{c}{ Closed Space } \\
\hline Latitude & Longitude & Latitude & Longitude \\
\hline 5.2425214 & 103.0538220 & 5.2468237 & 103.0512991 \\
5.2425214 & 103.0538221 & 5.2468248 & 103.051336 \\
5.2425216 & 103.0538222 & 5.2468282 & 103.0513374 \\
5.2425218 & 103.0538222 & 5.2468308 & 103.051339 \\
\hline
\end{tabular}

Sample errors in Degree of arc and distance Table 2 for closed space from the mean position unit $(\mathrm{m})$ for open and closed spaces shown in are much larger.

Table 2: The distance from mean position for open and closed spaces

\begin{tabular}{cccccccc}
\hline \multicolumn{4}{c}{ Closed Space } & \multicolumn{3}{c}{ Open Space } \\
\hline \multicolumn{2}{c}{ latitude } & \multicolumn{2}{c}{ Longitude } & \multicolumn{2}{c}{ latitude } & \multicolumn{2}{c}{ Longitude } \\
\hline Degrees & Meters & Degrees & Meters & Degrees & Meters & Degrees & Meters \\
\hline$-6.56 \mathrm{E}-05$ & -7.281 & $-5.81 \mathrm{E}-05$ & -6.45 & $3.51 \mathrm{E}-06$ & 3.896 & $1.24 \mathrm{E}-06$ & 0.14 \\
$-6.67 \mathrm{E}-05$ & -7.403 & $-9.50 \mathrm{E}-05$ & -10.55 & $3.51 \mathrm{E}-06$ & 3.896 & $1.14 \mathrm{E}-06$ & 0.13 \\
$-7.01 \mathrm{E}-05$ & -7.781 & $-9.64 \mathrm{E}-05$ & -10.70 & $3.31 \mathrm{E}-06$ & 3.674 & $1.04 \mathrm{E}-06$ & 0.12 \\
$-7.27 \mathrm{E}-05$ & -8.069 & $-9.80 \mathrm{E}-05$ & -10.88 & $3.11 \mathrm{E}-06$ & 3.452 & $1.04 \mathrm{E}-06$ & 0.12 \\
$-7.32 \mathrm{E}-05$ & -8.125 & $-5.87 \mathrm{E}-05$ & -6.52 & $2.91 \mathrm{E}-06$ & 3.230 & $9.38 \mathrm{E}-07$ & 0.10 \\
$-7.28 \mathrm{E}-05$ & -8.081 & $-2.93 \mathrm{E}-05$ & -3.26 & $2.71 \mathrm{E}-06$ & 3.008 & $8.38 \mathrm{E}-07$ & 0.09 \\
\hline
\end{tabular}

The results of satellites detected during of the satellites passing near the horizon. For experiment open space much stronger signals would be A sample of graphic plot by u-center indicates the sectors covered by different satellites at any specific time and the data from the red sectors are subject to large errors. More sectors appear in red in closed spaces due to the weak signals caused by obstruction as well as due to positions received as indicated by the light blue and yellow colours for which position data received are more accurate (Figures 8a and 8b). In semi enclosed spaces the receiver was only receiving signals from half of the hemisphere as the structures / buildings were blocking the signals.

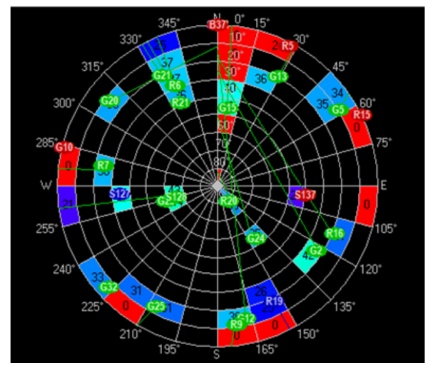

Figure 8a Satellites detected by u-centre for open space

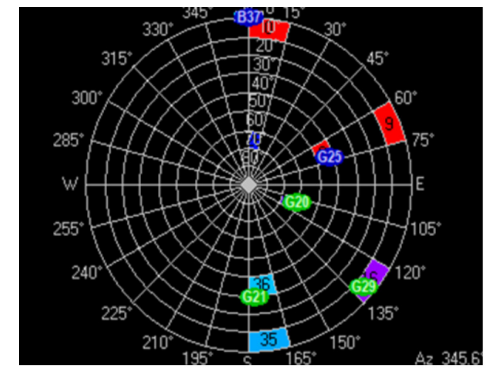

Figure $8 \mathrm{~b}$ Satellites detected by u-centre for closed space (The left side received no signals as the building acts as an obstacle) 
Position accuracy for open and closed spaces by u-center software

Figure 9 shows the results indicating the concentration of positions plotted at central

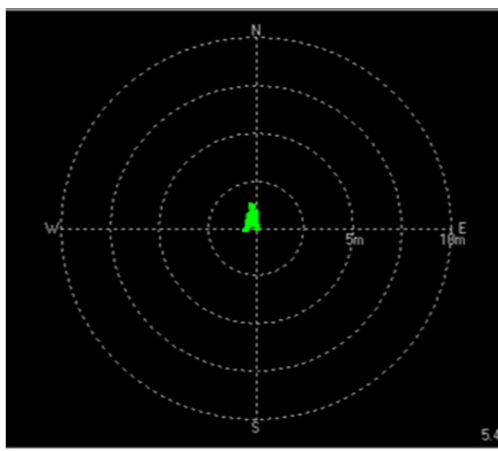

Figure 9: Plot of position data points obtained by u-centre software for open spaces

Positional error graphs for open and closed spaces

Figures 11 and 12 show the positional errors in meters from the mean position which clearly

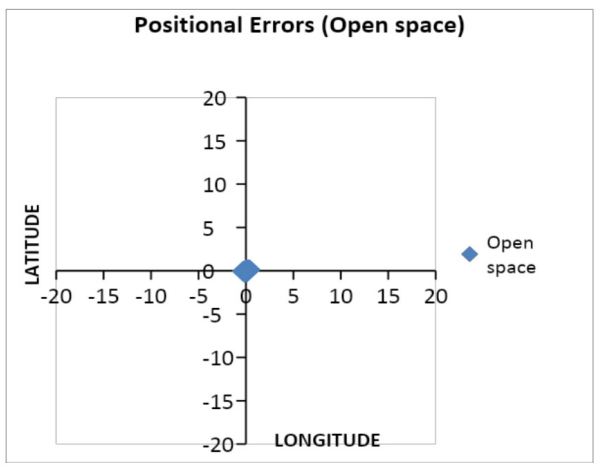

Figure 11: Graph pattern of position error for open spaces

\section{Statistical test for open and closed spaces}

The results of test statistic of latitude for open and closed spaces during the experiment are as shown in table 3 . The $\mathrm{F}>\mathrm{F}$ crit. indicates there position indicating high accuracy. The positions are shown to be more dispersed when plotted in closed spaces (figure 10) with more dispersion or error in longitude compared to latitude.

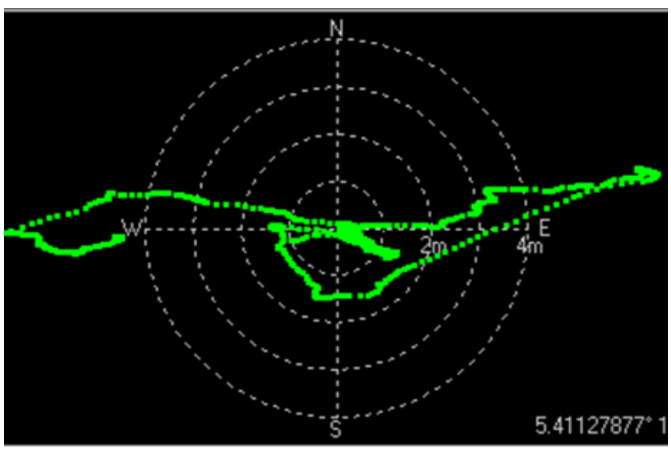

Figure 10: Plots of data of positions by u-centre software for closed spaces show larger error in longitude which are widely distributed compared to latitude error

indicate the errors are much more dispersed and larger for closed / semi enclosed spaces compared to positions acquired in open spaces.

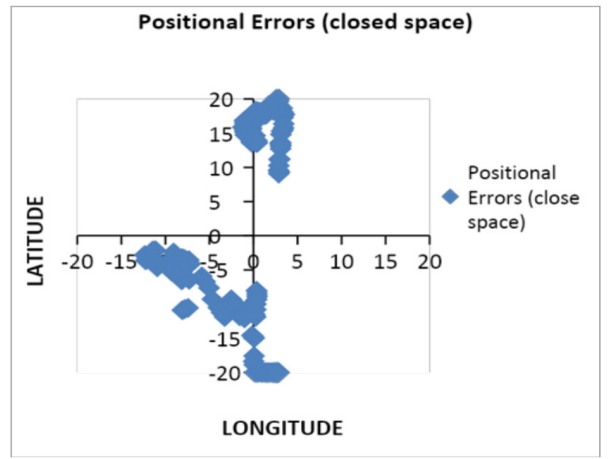

Figure 12: Graph showing pattern of position error for closed spaces (errors shows in meters)

is a significant difference for errors in latitude between open and closed spaces. Similarly, for longitude there is a significance difference in terms of positional error (Table 4). 
Table 3: Results of comparison errors of latitude between open and closed spaces

\begin{tabular}{lrrrr}
\hline \multicolumn{1}{c}{ SUMMARY } & \multicolumn{1}{c}{ Count } & Sum & Average & Variance \\
\hline Error-latitude-close & 30 & 13.16 & 0.439 & 0.023 \\
Error-Latitude-open & 30 & 5.143 & 0.171 & 0.012 \\
\hline
\end{tabular}

\begin{tabular}{|c|c|c|c|c|c|c|}
\hline Source of Variation & SS & $d f$ & MS & $F$ & P-value & F crit \\
\hline Between Groups & 1.072 & 1 & 1.072 & 60.77 & $1 \mathrm{E}-10$ & 4.007 \\
\hline Within Groups & 1.023 & 58 & 0.018 & & & \\
\hline Total & 2.095 & 59 & & & & \\
\hline
\end{tabular}

F: 60.77

Fcrit: 4.007

Table 4: The results comparison errors produced in longitude between closed spaces

SUMMARY

\begin{tabular}{lllll}
\hline Groups & Count & Sum & Average & Variance \\
\hline Error-Longitude-close & 31 & 19.42 & 0.627 & 0.775 \\
Error-Longitude-open & 31 & 2.23 & 0.072 & 0.006 \\
\hline
\end{tabular}

ANOVA

\begin{tabular}{lllllll}
\hline Source of Variation & SS & $d f$ & $M S$ & $F$ & P-value & F crit \\
\hline Between Groups & 4.768 & 1 & 4.768 & 12.21 & 0.0009 & 4.001 \\
Within Groups & 23.42 & 60 & 0.39 & & & \\
& & & & & \\
Total & 28.19 & 61 & & & & \\
\hline
\end{tabular}

\section{F: 12.21}

F crit: 4.001

In this case, $\mathrm{F}>\mathrm{F}$ crit, indicating there is a significant difference at $95 \%$ Confidence level for errors in longitude.

Overall, this project has achieved the stated objectives and the hypothesis in which the positional accuracy in open spaces is better than closed spaces due primarily to the reception of signals from more satellites passing in the atmosphere. This project also indicates that cheap, commercially available satellite antenna could be used to determine position for nonscientific purposes where precise positions are not required. In a totally enclosed spaces such as in a room at university the message "no fix" was displayed in the screen. Under such conditions the arriving signals are too weak or perhaps due to the low sensitivity of the antenna. In the presence of obstacles such 
as building half of the GPS signals could be effectively received by the antenna resulting in poor position fixing. Thus, for more critical job requiring more accurate location the antenna must be placed in open spaces.

\section{Conclusions}

The accuracy of the positions determined by using portable USB GPS antenna system shows the longitude has bigger errors compared to latitude error. In closed spaces, the errors are much more widely distributed compared to open spaces. The range of errors for closed spaces are such bigger than open spaces.

An ANOVA test indicate significant difference between the positions acquired in open spaces and closed spaces. The small errors in position do not affect the application of portable GPS for normal use. For a totally closed space, the weak signal display positions information with large errors.

\section{Acknowledgements}

Authors wished to thank the university for the research opportunity and the reviewers for the constructive comments towords this article.

\section{References}

Arnold, L. L., \& Zandbergen, P. A. (2011). Positional accuracy of the Wide Area Augmentation System in consumer-grade GPS units. Computers and Geosciences, 37(7), 883-892. https://doi.org/10.1016/j. cageo.2010.12.011

Deep, S., Raghavendra, S., \& Bharath, B. D. (2018). GPS SNR prediction in urban environment. Egyptian Journal of Remote Sensing and Space Science, 21(1), 83-85. https://doi.org/10.1016/j.ejrs.2016.09.002

Guo, J. Y., Li, G. W., Kong, Q. L., \& Wang, S. Y. (2014). Modeling GPS multipath effect based on spherical cap harmonic analysis. Transactions of Nonferrous Metals Society of China (English Edition), 24(6), 1874-
1879. https://doi.org/10.1016/S10036326(14)63266-0

Forin-Wiart, Marie Amélie, Pauline Hubert, Pascal Sirguey, and Marie Lazarine Poulle. 2015. "Performance and Accuracy of Lightweight and Low-Cost GPS Data Loggers According to Antenna Positions, Fix Intervals, Habitats and Animal Movements." PLOS ONE 10(6):1-21. Retrieved (http://dx.doi.org/10.1371/ journal.pone.0129271).

Marra, Alessio D., Henrik Becker, Kay W. Axhausen, and Francesco Corman. 2019. "Developing a Passive GPS Tracking System to Study Long-Term Travel Behavior." Transportation Research Part C: Emerging Technologies 104(October 2018):348-68. Retrieved (https://linkinghub.elsevier.com/ retrieve/pii/S0968090X18315729).

Shi, K., Xu, M., Jin, H., Qiao, T., Yang, X., Zheng, N., Xu, J., \& Raymond Choo, K. K. (2017). A novel file carving algorithm for National Marine Electronics Association (NMEA) logs in GPS forensics. Digital Investigation, 23, 11-21. https://doi. org/10.1016/j.diin.2017.08.004

Siła-Nowicka, K., \& Fotheringham, A. S. (2019). Calibrating spatial interaction models from GPS tracking data: An example of retail behaviour. Computers, Environment and Urban Systems, 74(November 2018), 136-150. https://doi.org/10.1016/j. compenvurbsys.2018.10.005

Skeivalas, J., Paršeliūnas, E., Putrimas, R., \& Šlikas, D. (2018). An influence of the correlation due tracking the same satellite on the accuracy of the GPS time dissemination. Measurement: Journal of the International Measurement Confederation, 121(February), 62-65. https://doi. org/10.1016/j.measurement.2018.02.048

van Dijk, Justin. 2018. "Identifying Activity-Travel Points from GPSData with Multiple Moving Windows." Computers, Environment and Urban Systems 70(September 2017):84-101. Retrieved (https://doi.org/10.1016/j. compenvurbsys.2018.02.004). 
Zeng, T., Sui, L., Jia, X., Lv, Z., Ji, G., Dai, Q., \& Zhang, Q. (2018). Validation of enhanced orbit determination for GPS satellites with LEO GPS data considering multi ground station networks. Advances in Space Research, 63(9), 2938-2951. https://doi. org/10.1016/j.asr.2018.06.012 